\title{
O justo e o legal a partir dos impactos ambientais no Pontal do Paranapanema: encontros e desencontros
}

\author{
Fair and legal from the environmental impacts in the Pontal do Paranapanema: \\ agreements and desagreements \\ Justa y legal de los impactos ambientales en el Pontal do Paranapanema: y \\ desacuerdos
}

Jefferson Hemerson Curado Camara Mestrando em Meio Ambiente e Desenvolvimento Regional, UNOESTE, Brasil jhccprudente@hotmail.com

\section{Bruno Magro Rodrigues}

Mestrando em Meio Ambiente e Desenvolvimento Regional, UNOESTE, Brasil magroamb@gmail.com

Munir Jorge Felício Professor Doutor em Geografia, UNOESTE, Brasil munir@unoeste.br 


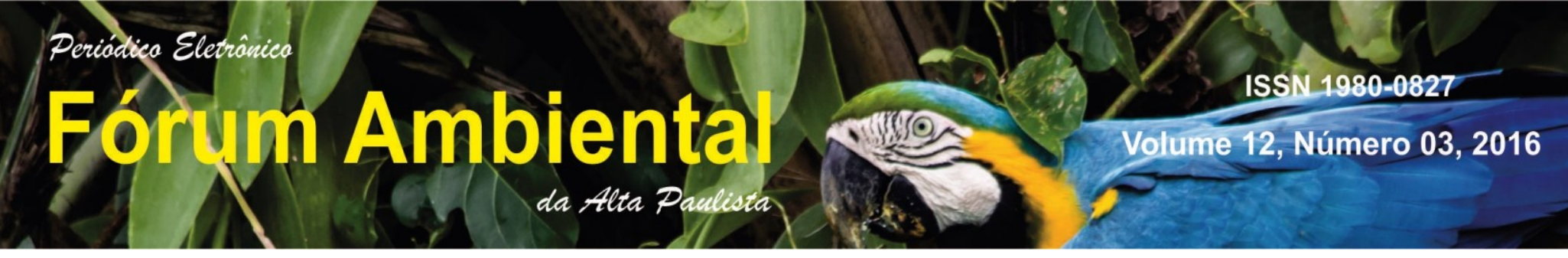

\title{
1 INTRODUÇÃO
}

Nos últimos anos tem se observado um expressivo crescimento quantitativo das lavouras de cana-de-açúcar em várias regiões do país, especialmente na região do Pontal do Paranapanema, onde imensas plantações de cana-de-açúcar avançaram sobre vastas regiões de pastagens e lavouras que antes eram destinadas à produção de alimentos.

De fato a cana-de-açúcar representa um importante produto agrícola para a economia do país, constituindo uma importante e inquestionável fonte de energia renovável. Contudo, a questão atinente aos danos ambientais decorrentes dessa cultura é indiscutível, afinal, o manejo dos praguicidas necessários para a prática dessa monocultura traz prejuízos para o meio ambiente e principalmente para os produtores que divisam suas propriedades com essas plantações, sem contar as comunidades locais.

Pautado no conhecimento que lhe é peculiar Felício (2012), leciona:

\begin{abstract}
O avanço do capital canavieiro com seu modelo de desenvolvimento territorial denominado agronegócio sucroalcooleiro nas terras do Pontal do Paranapanema é mais bem compreendido se não for analisado como um caso isolado e nem explicado numa única direção. Dito de outra maneira, o avanço do capital canavieiro não pode ser compreendido somente pela produtividade agropecuária como não deve ser entendido apenas pelos intensos conflitos fundiários.
\end{abstract}

Surge então a questão de se saber até onde é juridicamente legal que a atividade canavieira continue a atuar na região do Pontal do Paranapanema, fazendo uso do manejo da pulverização cujo malefício resulta a (deriva), e até onde é justo que tal atividade continue prejudicando o meio ambiente, os produtores que a margeiam, a vida e a saúde das comunidades próximas.

Daí importa dizer que Ferraz Junior (2003) está entre os doutrinadores cujas pesquisas se desenvolvem com a intencionalidade de determinar ou compreender se há algum código, forma, sentido racional ou irracional, capaz de legitimar o direito.

O problema que se enfrenta é de saber se existe alguma forma de razão, totalizadora e unificadora, que seja para o direito uma espécie de código doador de sentido, um sentido não adaptativo ao próprio direito e que nos permita estimá-lo como legítimo ou ilegítimo (FERRAZ JUNIOR, 2003, p. 344-345. Grifos no original).

Enquanto perdurarem as normas jurídicas dispostas em regras que de algum modo se adaptam às mudanças sociais, e por consequência aos interesses e à decisão dos conflitos, continuará havendo uma procura por uma estrutura resistente à mudança, mas, capaz de assegurar à experiência jurídica um sentido persistente. Assim, desde os primórdios foi nessa concepção que o direito buscou essa estrutura. Mesmo por que é necessário distinguir o que é justo do que é legal. O primeiro revela em sua grandeza um anseio social e o segundo emana dos códigos e das leis. 


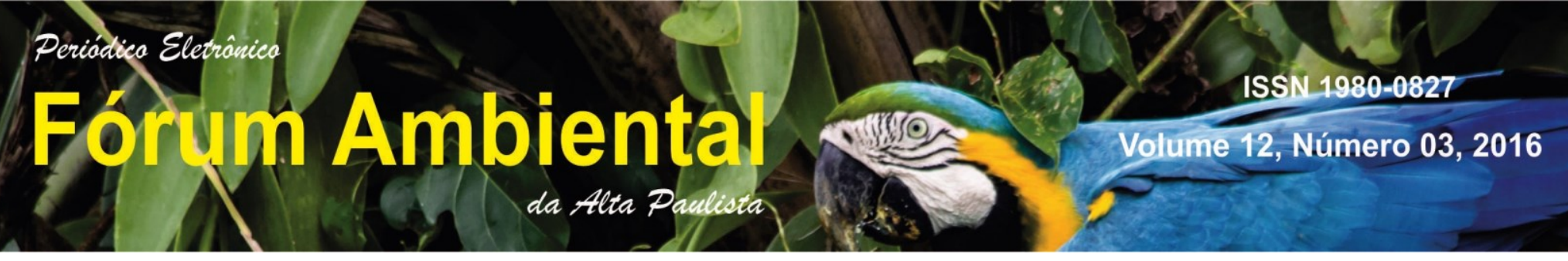

A análise abstrata do problema afeto à universalidade e racionalidade do conceito de justiça, leva-nos à visão de que nenhum homem pode sobreviver num universo moral, onde a justiça foi destruída ou postergada a segundo plano. Sem justiça não há sociedade. Pois, a justiça confere ao ser humano um sentido, uma razão de viver, um horizonte a ser buscado de forma constante e persistente. É por isso que o direito busca a justiça, como bem preconiza Ferraz Junior (2003, p. 345. Grifos no original): "o direito dever ser justo ou não tem sentido a obrigação de respeitá-lo."

Diante da ausência de senso de justiça o ser humano e a sociedade perdem o dever-ser do comportamento, sendo exemplo de tal alegação a circunstância afeta aos presos no tempo do Nazismo, condenados por crimes políticos, onde alguns tinham um sentimento de satisfação decorrente da consciência de haverem de algum modo contribuído para derrotar o regime, sendo capazes até mesmo de enfrentarem a morte. Daí decorre que a justiça, como código de ordem, se desrespeitada produz resistência e sua ausência leva à desorientação deixando, portanto, de se constituir um princípio doador de sentido para o universo jurídico.

Dois são os aspectos nos quais se baseiam as discussões modernas acerca da justiça classificando-a em aspecto formal - onde diante de um valor ético-social em situações bilaterais normativamente reguladas, exige-se a atribuição a alguém daquilo que the é devido. $E$, num segundo aspecto, a determinação daquilo que é devido a cada um. É justamente a conformidade ou não com critérios o que e a quem é devido, que reside o problema sob o enfoque material da justiça. $O$ código de lei ao regular a vida social torna-se auxiliar nas lides relacionais.

Aristóteles na Grécia Antiga em sua obra "Ética a Nicômaco" estabelece importante distinção, a partir da qual, justiça comutativa, conceituada como aquela que guarda proporção entre as coisas de sujeitos pressupostamente iguais entre si, e a justiça distributiva, marcada pelo conceito semelhante, divergindo apenas quanto aos sujeitos que são diferentes. Razões como essa contribuem para compreender o direito como inerente ao convívio social por auxiliar na busca de regular os interesses que são, necessariamente, conflitantes.

Para Ferraz Junior (2003) o substantivo razão, primitivamente tinha o significado de "tomar algo por algo", ligar "coisas" entre si, estabelecer relações. Porém, os romanos traduziram o conceito razão pela palavra "ratio" indicando conotação com as operações matemáticas. Esses exercícios tão próprios do universo jurídico propiciaram o desenvolvimento de um sem números de conceitos.

Com base nesses conceitos e com o decorrer do tempo racionalidade e irracionalidade começaram a conjugarem-se com a concepção de justiça e injustiça. Em poder do princípio de justiça surge a igualdade como um código de equilíbrio e distribuição de bens. Labora o princípio da igualdade com dois valores, que são o fato de haver ou não a igualdade, como bem salienta Ferraz Junior (2003):

Não se pode negar que, no correr dos séculos, racionalidade e irracionalidade conjugam-se com a ideia de justiça e de injustiça. Da mesma forma que os princípios da razão ora presidiam a forma do calcular e do pensar corretamente (lógica, metodologia), ora o sentido do agir corretamente (prudência, retórica), pode-se falar, analogicamente, em 


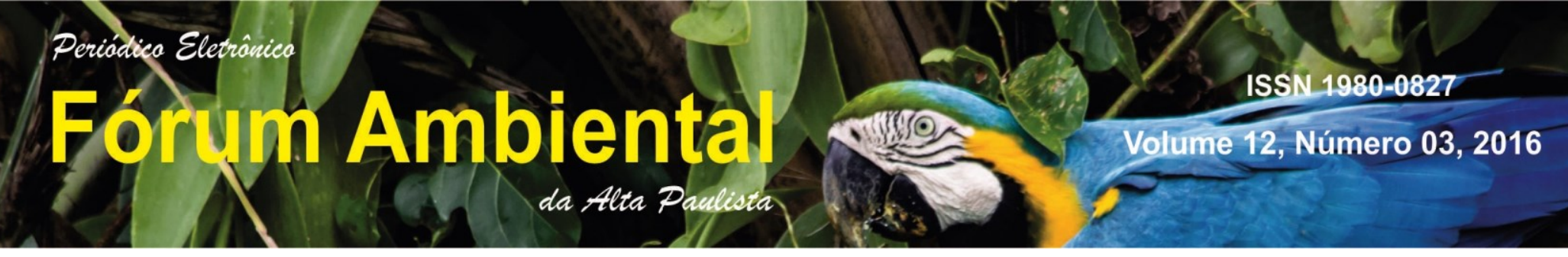

justiça como senso do equilíbrio na distribuição dos bens nas relações sociais (FERRAZ JUNIOR, 2003, p. 346).

Justiça e equidade se distinguem por ser a equidade fiel à igualdade, todavia, a mesma não pode ser generalizada, porque a equidade se generalizada leva à desigualdade, afinal, o que é equitativo em determinada situação, não pode ser em outra.

Sob o ponto de vista formal, o princípio da igualdade revela a justiça como um código racional, generalizada. Contudo, sua decodificação pode vir a ser mais ou menos rigorosa revelando graus de racionalização. Uma decodificação rigorosa admite desigualdades entre os membros da sociedade. Logo, o sistema de justiça material busca privilegiar a atividade utilitária do trabalho revelando que o que não é razoável é injusto.

Surge ai a necessidade da intervenção do Estado, como ente público, o qual por meio de encargos de direção e governo, como forma de estabelecer um tratamento proporcional às desigualdades cria as leis e com elas busca assegurar equilíbrio nas relações sociais. Para Ferraz Junior (2003) o principio da igualdade é a fonte de onde emana a equidade, pois:

O princípio da igualdade trabalha com dois valores e exclui um terceiro: ou
há ou não há igualdade. Não existe mais ou menos igual. Não obstante isso
é possível introduzir no princípio uma flexibilidade valorativa, desde que
decodifiquemos a igualdade conforme um código fraco. Isto é o que ocorre
quando associamos justiça e equidade, tomando esta como percepção da
igualdade no caso concreto (FERRAZ JUNIOR, 2003, p. 347. Grifos no
original).

Quando a decodificação é flexível e difusa, revelando-se num código fraco, nas relações sociais tidas como justas são passiveis de desigualdades entre seus membros, estribadas em posições de supremacia e inferioridade decorrente do que o sujeito é e não pelo o que pode obter.

O sistema de justiça material busca privilegiar o prestígio pessoal, variável e instável, aquele que presta obediência cega, contrariamente ao social, que abomina a entrega ao que é injusto. A autarquia do indivíduo busca uma valoração dos vínculos afetivos estribados no seio familiar, capazes de unir chefes patriarcais, bem como seus descendentes colaterais, agregados e afins. Portanto, um grupo familiar se firma basicamente num princípio de equidade, prevalecendo quanto à administração pública o reconhecimento de ser a mesma um patrimônio a ser explorado em proveito da amizade e da lealdade, da paz interior. Tais observações revelam que o princípio da igualdade leva à justiça um caráter de racionalidade e implementação de regras, sendo o direito um jogo de igualdade e desigualdades, constituindo suas "jogadas" ora decodificações "fortes ou fracas", variedades no tempo e espaço. São razões como essas que fazem em certas ocasiões o justo não coincidir com o legal.

De forma sucinta, justiça revela-se em princípio racional do jogo jurídico, sendo seu problema significativo permanente, esse último decorrente da interpretação das normas (aspecto material). Logo, a justiça quanto ao aspecto formal se dentro de seus limites, se justa ou injusta, é um problema da justiça material, mais precisamente dos princípios derivados da ética e de sua moralidade (material). 


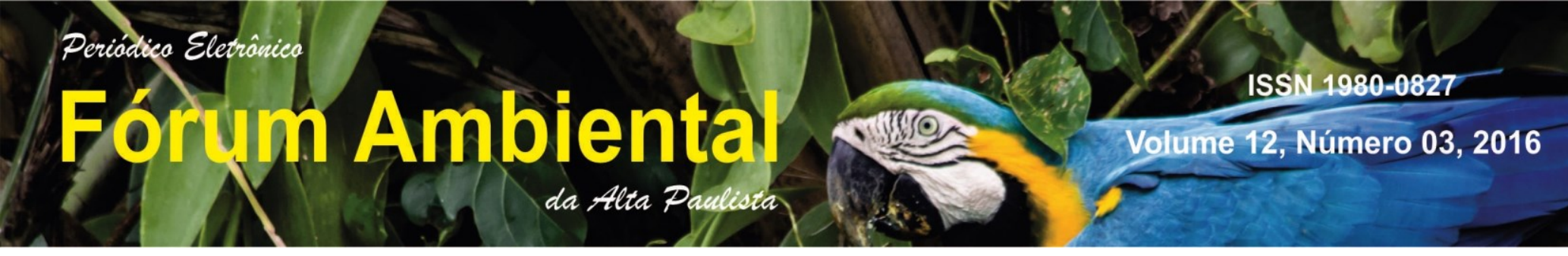

Afeto ao direito, Lyra Filho (2001) de forma didática e objetiva preconiza:

\begin{abstract}
Uma exata concepção do Direito não poderá desprezar todos esses aspectos do processo histórico, em que o círculo da legalidade não coincide, sem mais, com o da legitimidade, como notava, entre outros, inclusive o grande jurista burguês Hermann Heller. Diríamos até que, se o Direito é reduzido à pura legalidade, já representa a dominação ilegítima, por força desta mesma suposta identidade; e este "Direito" passa, então, das normas estatais, castrado, morto e embalsamado, para o necrotério duma pseudociência, que os juristas conservadores, não à toa, chamam de "dogmática".
\end{abstract}

Como exemplo da temática abordando o JUSTO e o LEGAL, cabe citar as perdas econômicas sofridas no exercício de 2010, pelos sericultores (criadores de bicho da seda) da região do Pontal do Paranapanema, ocasionados pela deriva (pulverização dos canaviais com agrotóxicos), fato esse que ocasionou a morte de grande parte dos casulos do bicho da seda daquela região. Citado fato, envolveu questões afetas ao desenvolvimento naquela região do setor sucroalcooleiro e os sericultores, de maneira a contribuir para um melhor conhecimento da legislação ambiental e consequente defesa do meio ambiente e do ser humano.

Assim, a leitura e compreensão do artigo 225으 da Constituição Federal, Lei 6.938/81 e demais dispositivos legais aplicáveis ao caso, bem como o estudo de teóricos como Milaré (2000), Antunes (1999), Fiorillo (2013), Carson (2013) Ihering (2003) e Kautsky (1986), levam a uma melhor compreensão do problema, auxiliando na prevenção, reparo e proteção do meio ambiente.

Insurge-se que ao longo do tempo o homem priorizou apenas em explorar a natureza e o meio ambiente, sem se preocupar com a escassez dos recursos naturais, visão essa que nos dias atuais não mais encontra sustentação, graças ao surgimento de uma conscientização global ou "globalização", onde se busca demonstrar a necessidade premente de preservar a vida no Planeta.

Também, é fato que durante séculos governos e empresas de forma produtiva e consumista, exploraram e degradaram em larga escala o meio ambiente, sem se preocuparem com o ocasionamento de danos ambientais.

Por isso, diante das significativas mudanças climáticas, tutelar os recursos ambientais tornouse necessário e imprescindível de modo a garantir o futuro da vida na terra. Logo, a concepção de que os recursos naturais são inesgotáveis e infinitos não é verdadeira, e, como consequência da exploração ambiental desenfreada e desregrada, surge impactos representados por doenças, desastres que se alastram pelo planeta, a exemplo do Brasil doenças como anencefalia, leucopenia, saturnismo, intoxicação ocasionada pelo excesso de agrotóxicos e mercúrio, como citado por (Milaré 2000).

[...] em todo o Brasil, a proliferação de doenças, como a anencefalia, a leucopenia, a asbestose, a silicose e o saturnismo, também não tem sabor de novidade; a intoxicação pelo uso desmedido de agrotóxicos e mercúrio vem constituindo grave problema de saúde pública; rios poluídos, autênticas galerias de esgoto; alimentos contaminados; cidades desumanizadas; 


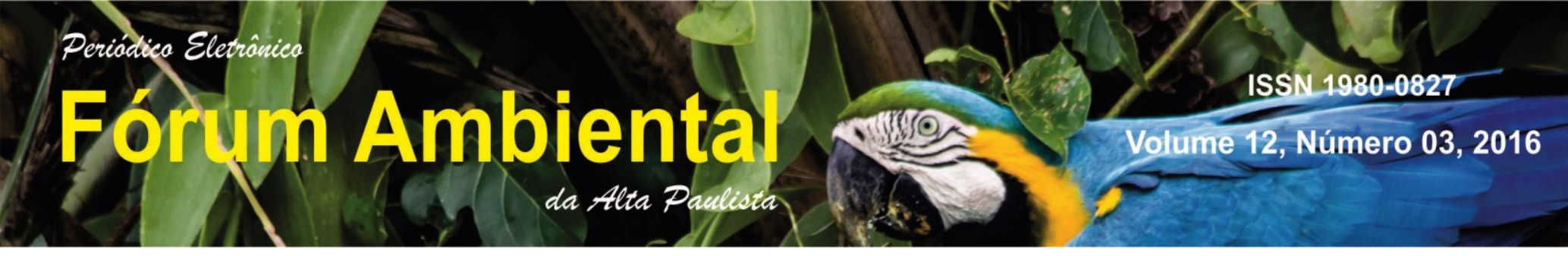

campos devastados etc. Tudo a demonstrar que, realmente, vivemos dias difíceis: o homem, como se disse alhures, que tanto correu para ser salvo pela técnica, agora corre para ser salvo da tecnologia (MILARÉ, 2000, p. 35).

Por exemplo, no que tange à monocultura da cana-de-açúcar, cultivada na região do Pontal do Paranapanema, cediço que a aplicação de elevadas doses de agrotóxicos (alguns até de uso proibido pela legislação Brasileira) com vistas ao aumento da produtividade são praticados pelas Usinas produtoras, acarretando danos ambientais nas mais variadas modalidades.

É por conta de reprovável conduta que os sericultores da região do Pontal do Paranapanema, estão sofrendo, havendo a urgente necessidade de se atentar a essa problemática, na busca novas técnicas e alternativas voltadas ao desenvolvimento sustentável, mas, acima de tudo de preservação ambiental com vistas à geração futura.

Como forma de demonstrar a emergente preocupação a nível mundial quando o tema é preservação do meio ambiente, podemos citar a Eco 92, e a Conferência das Nações Unidas para o Meio Ambiente e o Desenvolvimento (CNUMAD) realizada no mesmo ano no Estado do Rio de Janeiro.

A temática da sustentabilidade percorreu as discussões durante as conferências mundiais tentando encontrar formas para harmonizar as necessidades humanas com os recursos naturais para que a sociedade se desenvolvesse de modo sustentável. Foram elencados alguns princípios fundamentais como exposto por MILARÉ (2000).

Meio ambiente e consumidor são palavras que do ponto de vista da legislação Brasileira se equivalem, ou seja, são colocados em paridade, lado a lado. Em consequência disso o legislador Brasileiro coloca o Estado e a coletividade como tutores e guardiões desses recursos naturais, editando normas voltadas à proteção e punição daqueles que lesam o meio ambiente (pessoas físicas ou jurídicas), buscando inclusive a reparação civil decorrente do mau uso e dos danos ocasionados ao meio ambiente e a terceiros, exemplo disso é a redação emanada do artigo 14, § 1ㅇda Lei 6.938/81, recepcionada pelo artigo 225, § 3ㅇ da Constituição Federal.

Matheus Junior (2015), em recente monografia, abordando a questão afeta à tutela e a questão agrária no Pontal do Paranapanema, discorreu acerca do tema em foco, tecendo as seguintes considerações:

Ao ampliar a compreensão sobre o significado da qualidade de vida para a natureza e para o ser humano pode ajudar a perceber a intenção do legislador quando esculpiu o "caput" do art. 225 da CF ao afirmar que:

Art. 225. Todos têm direito ao meio ambiente ecologicamente equilibrado, bem de uso comum do povo e essencial à sadia qualidade de vida, impondose ao Poder Público e à coletividade o dever de defendê-lo e preservá-lo para as presentes e futuras gerações.

É desejo do legislador colocar o Estado e a coletividade como guardiões dos recursos naturais contribuindo para sua preservação, como já estava no comando legal do art. 20 da lei 6.938/81, lei que fora recepcionada pela Constituição Federal, da seguinte forma: 


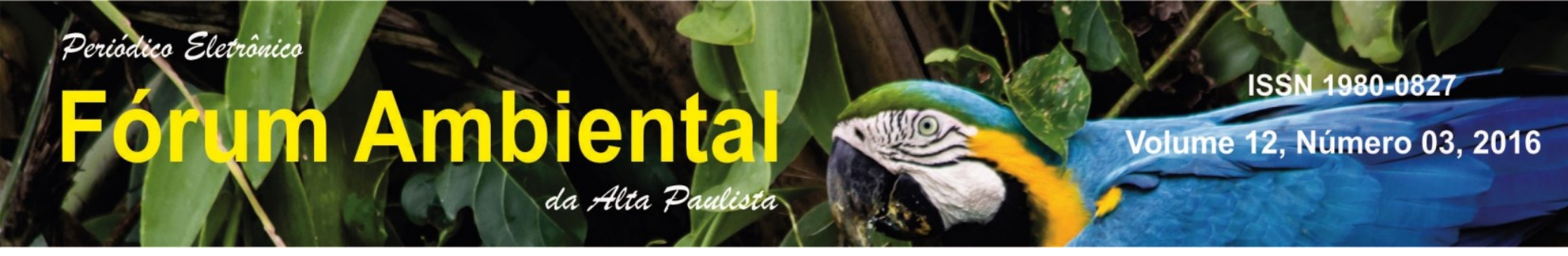

Art. 2ㅇ - A Política Nacional do Meio Ambiente tem por objetivo a preservação, melhoria e recuperação da qualidade ambiental propícia à vida, visando assegurar, no País, condições ao desenvolvimento socioeconômico, aos interesses da segurança nacional e à proteção da dignidade da vida humana.

Neste sentido também cabe a analise do artigo 1 으 e seus incisos I e II da lei № 7.347 de 1985, a proteção ao meio ambiente como bem de uso comum do povo e a proteção do consumidor como hipossuficiente diante da estrutura social, conforme segue:

Art. 1ำ Regem-se pelas disposições desta Lei, sem prejuízo da ação popular, as ações de responsabilidade por danos morais e patrimoniais causados:

I - ao meio-ambiente;

II - ao consumidor;

Nestes três marcos jurídicos de tutela ambiental ressalta-se a importância da lei 6.938/81 por fazer emergir a Política Nacional de Meio Ambiente como vige no seu art. $2{ }^{\circ}$, inciso I ao estabelecer o meio ambiente como patrimônio público, assegurado e protegido, haja vista o uso em comum e coletivo, como se infere:

Art. 2ㅇ - A Política Nacional do Meio Ambiente tem por objetivo a preservação, melhoria e recuperação da qualidade ambiental propícia à vida, visando assegurar, no País, condições ao desenvolvimento socioeconômico, aos interesses da segurança nacional e à proteção da dignidade da vida humana, atendidos os seguintes princípios:

I - ação governamental na manutenção do equilíbrio ecológico, considerando o meio ambiente como um patrimônio público a ser necessariamente assegurado e protegido, tendo em vista o uso coletivo.

Portanto, na busca de uma solução para o conflito atualmente vivenciado no Pontal do Paranapanema pelos sericultores e produtores sucroalcooleiros, é que se deve proporcionar a retomada de discussões e análises sobre essa questão. Daí quanto á relação sericultura/produção sucroalcooleira na região do Pontal do Paranapanema, emerge a necessidade da adoção de uma série de medidas voltadas a mudar esse cenário, de modo que a discussão de projetos e outras medidas voltadas para o tema venham ampliar a compreensão não apenas sob o ponto de vista jurídico, mas, também, da sociedade como um todo.

Por tal razão a importância dos diálogos estabelecidos com diversos autores, com vistas a conhecer suas análises voltadas a melhorar a discussão e a abrangência do tema agrário e da tutela ambiental. E como resultado, asseverou haver realizado leituras bibliográficas acerca da questão agrária e a tutela ambiental no desenvolvimento da agricultura na Região do Pontal do Paranapanema.

As discussões no campo científico permeiam o início do século XXI, por conta da necessidade: da garantia e eficiência econômica, preservação dos recursos naturais e promoção da equidade social. A pesquisa propiciou uma melhor compreensão dos impactos ambientais, e de como se estabelece essa tutela voltada a proteger, preservar e conservar o meio ambiente. 


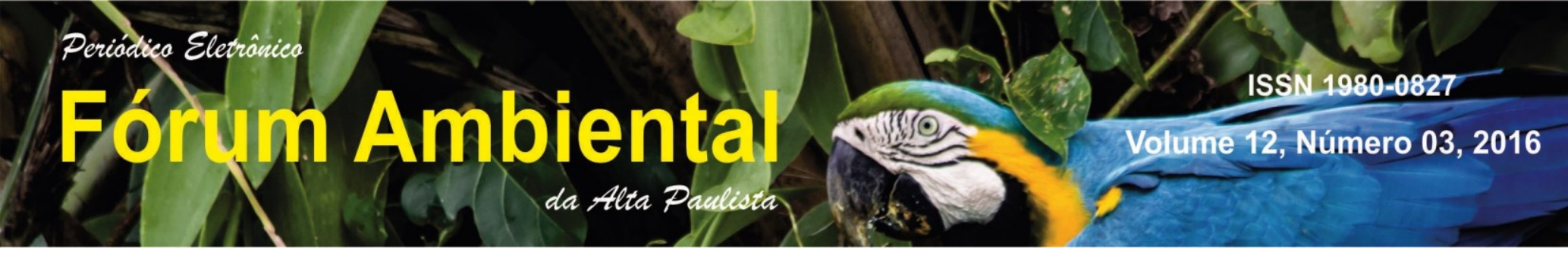

Por fim, vale dizer que a questão ambiental em suas diversas formas colocam as gerações futuras em risco, revelando-se aí a urgente necessidade de novas concepções de sustentabilidade teórica, jurídica, política e econômica.

Enfim, é de se perguntar: Até onde é possível afirmar que o modelo capitalista está na origem dos problemas ambientais sofridos pelo homem?

Historicamente poderia se dizer que é possível provar que o capital sempre encontrou uma forma de utilizar ilimitadamente os recursos naturais existentes no globo, de modo a obter os melhores e mais baratos meios de produção.

\section{OBJETIVOS}

Relacionar a atividade da monocultura da cana-de-açúcar, onde a pulverização aérea por meio da deriva, através dos praguicidas utilizados contaminam propriedades no entorno da atividade agrícola. Discutir sobre a efetividade dos encontros e desencontros entre o justo e o legal a partir dos impactos ambientais no Pontal do Paranapanema, verificando em que momento da evolução jurídica o meio ambiente é erigido à categoria dos direitos e deveres fundamentais.

\section{METODOLOGIA}

O desenvolvimento desse trabalho foi impulsionado pela leitura das ideias de autores, visando compreender suas análises, por meio das quais, os debates iniciados indicam importantes contribuições das ciências jurídicas como ciência que busca tutelar o meio ambiente.

Buscou-se, também, a reflexão das concepções de cada autor, verificando a atualidade delas e debatendo as perspectivas advindas do avanço e do aperfeiçoamento tecnológico.

Foi utilizada a lógica dedutivo-indutiva, através da pesquisa bibliográfica, com a identificação de conceitos importantes, interpretação jurídico e ambiental relacionados com o objeto de estudo, pela técnica de documentação indireta e bibliográfica, para alcançar os objetivos propostos foi necessário, também, realizar uma pesquisa bibliográfica, exploratória, ancorado no método empírico-analítica e histórica, com abordagem de pesquisa diagnóstica.

A região que compõe o corpus de análise, conforme proposta é aquela que concentra os assentamentos rurais localizados na Região do Pontal do Paranapanema.

\section{RESULTADO}

O resultado decorrente da observação da presente pesquisa possibilitou compreender que a atividade sucroalcooleira desempenhada pelas usinas de cana de açúcar na região do Pontal do Paranapanema é sem sombras de dúvidas do ponto de vista jurídico considerada legal.

No entanto, observa-se não ser justo que os resultados decorrentes da deriva oriunda do manejo da pulverização dos canaviais, conforme explicitado continuem a afetar a saúde, a vida da população, produtores agrícolas que divisam com essas lavouras, assim como prejudicando o meio ambiente num todo. 


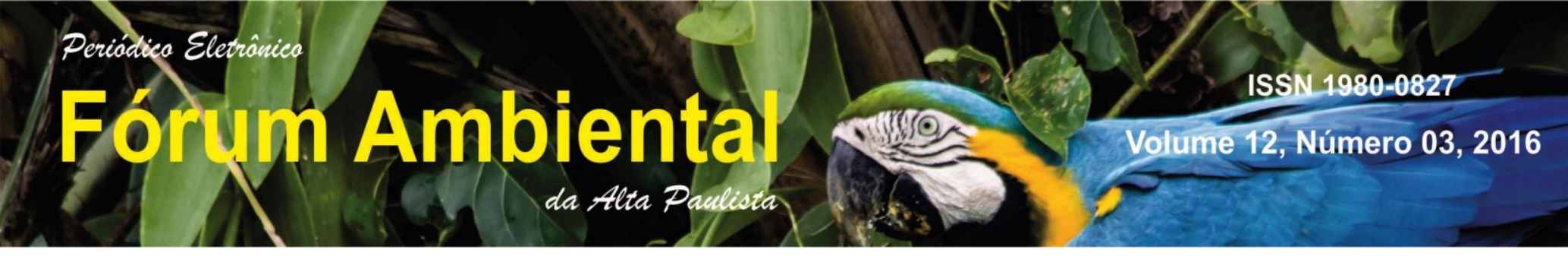

\section{CONCLUSÃO}

É sabido que a alternativa por fontes de energia limpas e renováveis tem sido uma busca constante almejada por várias nações espalhadas pelo globo. De outro lado tem-se que a implementação e instalação dos empreendimentos industriais na região do Pontal do Paranapanema, têm ocasionado impactos variados, seja de ordem econômica, social, como também, ambiental.

Ao se debruçar sobre a questão da cultura da cana-de-açúcar nota-se que a dimensão dos impactos socioambientais decorrentes da sua prática, se revela num grande problema para as regiões onde a mesma é desenvolvida, muito embora entendam alguns que os empregos gerados pelo setor justifiquem a continuidade de malgrada atividade agrícola.

Fosse apenas à exigência de grandes extensões de terra necessária para a viabilidade da cultura, porém, como já asseverado o manejo dessa cultura envolvendo a prática da pulverização aérea a qual tem como resultado a deriva, revelando assim o urgente e necessário encontro de solução para a pulverização que tem como consequência a deriva.

Por fim, denota-se preciso e urgente à criação de uma legislação capaz de regulamentar e disciplinar de forma "justa" e adequada o manejo da monocultura da cana-de-açúcar, de modo a cessar os prejuízos causados pela deriva da pulverização aérea ao meio ambiente, aos produtores e comunidades que divisam ou estejam situadas próximas a essa cultura.

Por meio do presente trabalho se vislumbra a necessidade da conscientização da sociedade para um despertar onde se constata ser o agronegócio oneroso para a população, e particularmente o meio ambiente, situação essa que interessa apenas ao capitalismo como a anuência do Estado.

\section{REFERÊNCIAS BIBLIOGRÁFICAS}

FELícIO, Munir Jorge. PROJETO - DESDOBRAMENTOS DA QUESTÃo AGRÁRIA NO PONTAL do PARANAPANEMA. Presidente Prudente: Unoeste - Universidade do Oeste Paulista, projeto apresentado no XXI Entro Nacional de Geografia Agrária realizado pela UFU - Universidade Federal de Uberlândia 2012.

LYRA FILHO, Roberto. O QUE É DIREITO. 17ạ edição. 4a reimp. São Paulo: Editora Brasiliense, 2001.

MATEHUS JUNIOR, Delwek. MONOGRAFIA - A TUTELA AMBIENTAL E A QUESTÃo AGRÁRIA NO PONTAL DO PARANAPANEMA. Presidente Prudente: Unoeste - Universidade do Oeste Paulista, 2015.

FERRAZ JUNIOR, Tércio Sampaio. INTRODUÇÃO AO ESTUDO DO DIREITO - TÉCNICA, DECISÃO, DOMINAÇÃO. São Paulo. Editora Atlas S.A 2003. 4a Edição revista e ampliada

MILARÉ, Édis. DIREITO DO AMBIENTE: DOUTRINA, JURISPRUdÊNCIA, GLOSSÁRIO. São Paulo: Ed. Revista dos Tribunais, 2000. 